\title{
A Conceptual Model for Situating Purposes in Artificial Institutions
}

\section{Um modelo conceitual para situar propósitos nas instituições artificiais}

\author{
Rafhael R. Cunha ${ }^{1,2 *}$, Jomi F. Hübner², Maiquel de Brito ${ }^{3}$
}

\begin{abstract}
In multi-agent systems, artificial institutions connect institutional concepts, belonging to the institutional reality, to the concrete elements that compose the system. The institutional reality is composed of a set of institutional concepts, called Status-Functions. Current works on artificial institutions focus on identifying the status-functions and connecting them to the concrete elements. However, the functions associated with the status-functions are implicit. As a consequence, the agents cannot reason about the functions provided by the elements that carry the status-functions and, thus, cannot exploit these functions to satisfy their goals. Considering this problem, this paper proposes a model to express the functions - or the purposes - associated with the status-functions. Examples illustrate the application of the model in a practical scenario, showing how the agents can use purposes to reason about the satisfaction of their goals in institutional contexts.

Keywords: Purposes - Status-Functions - Artificial Institutions — Multi-Agent Systems

Resumo: Em sistemas multiagentes, instituições artificiais conectam conceitos institucionais, pertencentes a realidade instituticional, em elementos concretos que compõem o sistema. A realidade institucional é composta de um conjunto de conceitos institucionais, chamados de funções de status. Trabalhos atuais em instituições artificiais focam em identificar as funções de status e conectá-las aos elementos concretos. Entretanto, as funções associadas com as funções de status são implícitas. Como uma consequência, os agentes não conseguem raciocinar sobre as funções fornecidas pelos elementos que carregam as funções de status e, portanto, não conseguem explorar essas funções para satisfazer seus objetivos. Considerando esse problema, esse trabalho propõe um modelo para expressar as funções - ou os propósitos - associados com as funções de status. Exemplos ilustram a aplicação do modelo em um cenário prático, mostrando como os agentes podem usar os propósitos para raciocinar sobre a satisfação de seus objetivos no contexto institucional.

Palavras-Chave: Propósitos - Funções de Status - Instituições Artificiais - Sistemas Multiagentes

${ }^{1}$ Federal Institute of Education, Science and Technology of Rio Grande do Sul (IFRS), Vacaria - Rio Grande do Sul, Brazil

${ }^{2}$ Dept. of Automation and Systems Engineering, Federal University of Santa Catarina (UFSC), Florianópolis - Santa Catarina, Brazil

${ }^{3}$ Control, Automation, and Computation Engineering Department, Federal University of Santa Catarina (UFSC), Blumenau - Santa Catarina, Brazil

*Corresponding author: rafhael.cunha@posgrad.ufsc.br

DOI: http://dx.doi.org/10.22456/2175-2745.110830 • Received: 20/01/2021 • Accepted: 08/10/2021

CC BY-NC-ND 4.0 - This work is licensed under a Creative Commons Attribution-NonCommercial-NoDerivatives 4.0 International License.
\end{abstract}

\section{Introduction}

Consider a scenario where (i) an autonomous computer system named $s B o b$ acts on behalf of the user Bob to achieve the goal of having a book and (ii) an autonomous computer system named sTom acts on behalf of the user Tom to sell a book. To this end, (i) $s B o b$ needs to execute an action that means giving a value and exchange for a good, and (ii) sTom waits until $s B o b$ executes an action with such meaning and then deliver the book. The goals of both the systems are social goals because they depend on a common interpretation involving certain facts. Without such common interpretation, $s B o b$ might not know which action to perform to give a value in exchange for the book. Even this would not be the case, sTom might not acknowledge the action of $s B o b$, refusing thus to deliver the book.

Agents and Multi-Agent Systems (MAS) are suitable approaches to develop systems such as the previously described. MAS are systems composed of autonomous computational entities, henceforth referred to as agents, that can interact within a dynamic environment to achieve their common and/or individual goals [1]. The interaction among the agents is in the very core of MAS that is thus a useful approach to handle computational problems involving social aspects [2]. In the example, both $s B o b$ and $s T o m$ can be considered agents, and 
the highlighted problem is the common interpretation about certain facts.

Inspired by human societies, some works propose models and tools to provide this kind of interpretation to computer systems and, in particular, to MAS [3]. They usually consider that the elements involved in the interaction among the agents constitute (or count as) institutional concepts, that are the common interpretation of those concrete elements [4, 5, 6, 7]). For example, agents acting in an e-commerce scenario may constitute (or count as) buyers, while some of their actions may count as payments. These institutional concepts are referred in the literature as status-functions: they are status that assign functions to the concrete elements [8,9]. For example, the status buyer assigns to an agent some functions such as perform payments, take loans, etc. Artificial Institutions are the component of the MAS that is responsible for defining which conditions must be considered for an agent to become a buyer, or an action to become a payment $[8,9]$.

The existing works on Artificial Institutions are concerned with identifying and constituting status-functions. However, they focus more on the status than the function. While the status is explicit, the function is implicit. In other words, the literature, as far as we know, does not provide the means for the institution to express the functions associated with the status explicitly. The main drawback of this limitation is that agents cannot reason about the functions performed by the elements that carry some status. As a consequence, they cannot exploit these functions to satisfy their goals. In the previously described scenario, the artificial institution does not make explicit to the agents that the payment has a function associated to giving a value and in exchange to receive a good and thus can satisfy their goals of having and selling a book respectively.

There are some drawbacks of not specifying the functions attached to the status in MAS's institutional specification. First, different agents with similar goals may have problems to achieve their goals, even running in the same environment and institution. It is especially critical in open MAS, where the agents can be designed and implemented by different parties and it is not possible to predict, in design time, neither the number, nor the behaviour, nor the way the agent shall interact among themselves and explore the available resources [10, 11]. For example, in the library scenario, the payment statusfunction can have the function of bringing the system to a new state of the world that the agent that executed the payment will have the book. In this case, have a book is the function of the payment status-function interpreted by agents' perspective. Consider that Alice entered in our example involving Bob and Tom. Alice has the goal of acquiring a book. In the first moment, both Bob and Alice's goals appear to be similar. However, since it is difficult for agents to reasoning about the functions associated with status-functions, Alice will only reach her goal if she changes her code to be similar to the $B o b$ code. Second, the same agent can trouble to reach his goal if it moves itself to a new environment and institution similar to the previous (but remain with the same goal). For example, remember that Bob has the goal of have a book and was developed to run in a book store scenario. If he changes to a library scenario, it will probably need to change his code or the environment or institution code. It occurs because in this new scenario, have a book can be reached by another function that is not associated with payment status-functions. The agents cannot understand the functions associated with the status-functions that make the institution.

Proposals of artificial institutions were studied on [12, 6, $5,13,14]$ considering the effective implementations of institutions in computational systems. Although the works on artificial institutions focus on supporting the regulation of the system, they can also help the agents reach their goals [15]. From those examples and explanations, we consider that the interpretation of a status-function is related to its purposes (i.e., the new state of the world that the agent executing that function will bring to). Therefore, we can conclude that (i) the meaning of a status-functions is related to its purposes and (ii) the agents' goals can be related to those purposes. Nonetheless, artificial institutions, as currently conceived, do not specify the purposes associated with status-functions. That is, they do not support to agents' reasoning [15]. Considering these issues, the main contribution of this paper is a conceptual model to express the purposes associated with the status-functions that composes the artificial institutions presents on the MAS. For this, we will use as inspiration the Construction of the social reality by John Searle [8, 9] and Documentality by Maurizio Ferraris [16] both philosophers' theories that seem to be fundamental for comprehend the social reality.

This paper is organized as follows: Sect. 2 shows the subjects necessary to understanding the work. It includes philosophical theories and related works. This section aims to help the reader to understand the philosophical concepts involved in this work and its differences concerning the others. Sect. 3 presents the proposal of the theoretical model. Initially, the section presents an overview of the model, explaining our understanding of some philosophical concepts used in this work, and later these concepts are defined mathematically. In this paper, we focus on the conceptual level of the proposed model. Some examples illustrating how the model can be used in MAS scenarios are demonstrated in the Sect. 4. Finally, Sect. 6 presents some conclusions about this work and suggests future works.

\section{Background}

This section presents the background needed for understating our approach. Our model is strongly based on some philosophical concepts and theories presented in Subsection 2.1. It is essential that the reader understands the concept of purposes and why they are related to the agents' practical interests. This is the key concept of this work. Finally, in Subsection 2.2, some related works that implement artificial institutions are presented. Also, the differences between those works and this one are discussed. 


\subsection{Institutions according to John Searle}

The Institutional Reality is part of a wide concept of social reality proposed by John Searle [8,9]. Searle argues that there are facts, called brute facts, that can be explained by the basic sciences and are objectives, i.e., they do not depend on the perception or mental state of any individual (e.g. water is composed of hydrogen and oxygen). However, there are some facts that, even being objective, depend on the beliefs of the individuals. For example, a piece of paper and an individual are not considered, respectively, as money and president solely due to their physical characteristics. The basic sciences cannot explain that a piece of paper is money and that a citizen is the president. For a piece of paper to be used as money or a human being to be recognized as president and both can perform their functions accordingly, it is necessary that members belonging to a community collectively accept or recognize that the object, person, etc., is considered as money, president, etc. For this reason, these facts are considered social facts.

A subclass of social facts is institutional facts. These facts exist only within human institutions. Thus, an institution is defined by institutional facts. For example, two people moving pieces on a board at random is a social fact. Two people respecting rules and moving pieces according to their meanings on a board can be considered a game, and in this case, it is an institutional fact because they are in the context of an institution (the game of chess, in this case) [9]. The institution (e.g., chess game) assigns meaning to the pieces and movements performed in the game. Without the institution, there would be no plays like checkmate, $\mathrm{Zug}$, or pieces like a queen, king, etc.

According to Searle, institutional facts are based on statusfunctions and constitutive rules. Status-functions refer to statuses that have associated functions. These statuses enable concrete elements to perform functions (associated with status) that cannot be explained through their physical virtues. Constitutive rules are the way that we assign status-functions to concrete elements with the following formula: $X$ count-as $Y$ in $C$. For example, a piece of paper count-as money in a bank, where $\mathrm{X}$ represents the concrete element, $\mathrm{Y}$ the statusfunction and $\mathrm{C}$ the context where that attribute is valid. The assignment of status-functions requires the society to agree about this, i.e., establish a collective agreement [8, p.44].

According to Searle, an object will have a function imposed on it when the object is used for a certain purpose [9, p.58]. Purposes are the practical interests of the individuals that are satisfied by some function assigned to a status. Since the institution is formed by people and their collective agreements [8], it is possible to say that the people themselves (through their purposes) assign meaning to the statusfunctions. The functions associated with the statuses are called agentive functions because they are assigned from practical interests of the agents [8, p.20]. For example, when we say "checkmate" in a chess game, we are putting the function of winning the game in a chess piece. This function does not occur naturally; it is assigned through the practical interest of some agents playing the game (i.e., under that context). This practical interest is actually the purpose for which the function has been assigned. Fundamentally, both agents involved in the game must have the same understanding of these facts (i.e., about the function and your purpose). Otherwise, none of them achieve their goal. In other words, the chess piece that is constituting a status (e.g. king) may execute a function associated with that status (e.g checkmate). Searle asserts that someone must be capable of understanding what the thing is for, or the function could never be assigned [8, p.22]. Understanding a function requires to understand for what it serves (i.e., your purpose). In the case of chess game, the purpose of function "checkmate" is to win the game. This purpose is in line with the interests of the agents who are playing the game (i.e. this is understood by the people involved in the institution).

While Searle suggests that status-functions are a consequence of collective intentionality, their origin remains, at least in part, unexplained. For example, throughout history, human societies agreed on assigning the function of money to a piece of paper, a shell or a portion of salt. However, the function seems not having a genesis. It is hard to establish when money or any other social objects were invented. It is also even more difficult to explain the nature of the collective intentionality that motivates people to act in different ways when they have contact with a concrete element constituted with a status. In other words, it is not clear the purposes associated with the status-functions.

To address the mentioned issues, Ferraris $[17,16]$ proposes to observe the social reality in a deep level, less intuitive, where the reality is grounded by structures called Documentality. These structures of documents store speech acts that not only describe or prescribe, but they actually build social objects. Such a structure makes it possible to explain the staying and persistence of functions (and their purposes) associated with status over time. The speech acts that gave origin to functions and status were written and stored in documents that run through time. Making possible for the people to learn theses structures through study, perception, etc. For example, the money has functions (buying, selling, etc.) that can be used only if the individuals who are using the social object remember these functions based on their memory. To summarize, social objects rescue memories in individuals that allow them to use those memories (i.e., the functions associated with statuses) that have been assigned to the social object.

From this, it is possible to conclude (i.e., through of the theories) that an additional system of elements is required so functions, values and status can persist and have value recognized over time within the social reality [17]. Such a system can also bring benefits to the MAS scenario, where the system indicate a useful way of understanding the statusfunctions that composes the institutional reality. It will permit to improve the agents' reasoning about the satisfaction of their goals and overcome the difficulties that motivate the realization of this work. 


\subsection{Institutions in MAS}

The main idea of using artificial institutions as a counterpart of human institutions in computer systems has inspired works in MAS. In different ways, these works use the count-as relationship, established through the constitutive rules proposed by Searle, to regulate the systems. In this work, the countas relationship is considered, as well as other concepts (e.g., Status-Function, norms, etc.), as components of the institutional reality in MAS. The purpose of this section is to review state of the art in this area of knowledge. The question to be answered is: How do artificial institutions have the means to represent the abstract elements that make up the institutional reality?

From the analysis carried out, it is observed that all works that develop artificial/electronic institutions are inspired by the theory of the philosopher John Searle [8,9] and are marked by an exclusively normative purpose. Some works present functional approaches. They relate brute facts to normative states (e.g., a given action counts as a violation of a rule). These works do not involve ontological issues, and, therefore, it becomes even more difficult to support the meaning of abstract concepts present in the institutional reality. Other works show ontological approaches, where brute facts are related to concepts used in the specification of norms (e.g., sending a message counts as a bid in an auction). However, these works have some limitations that are discussed below.

According to Table 1, there are solutions [24, 7, 6, 5, 21, $20]$ that allow agents to know and reason about constitutive and normative rules. In fact, some institutional specifications allow agents to interpret rules in order to satisfy normative conditions. However, generally the status-function $(Y)$ is just a label assigned to the concrete element $(X)$ and used in the specification of the regulative norms. Therefore, $Y$ does not seem to have any other purpose than to serve as a basis for the development of stable regulative norms $[19,20]$. Some exceptions to the described pattern are in the works of [25, 26, 7, 27] where $Y$ represents a class formed with some properties as roles responsible for executing actions, time to execute them, condition for execution, etc., [19] where $Y$ is a general concept, and $X$ is a sub-concept that can be used to explain $Y$ and, in general, in classified works as functional. Although the exceptions contain more information than just an abstract concept in the $Y$ element, these data are somehow associated with regulatory standards. The agent until is able to reason and understand what actions can be performed in the environment to satisfy the normative specifications. However, because there is no model that explains the meaning of these actions in the institutional context, the agent may have difficulties in understanding that the actions performed can also satisfy their social objectives. For example, the meaning have a book is related to payment status-functions. Considering the previously described example of selling books, there is currently no way for Bob and Tom to understand that the actions performed, if interpreted through their purposes (i.e., their meanings), can also satisfy their objectives.
The limitation discussed above indicates the need to develop a model that explains the meaning (i.e., the purposes) of status-functions belonging to institutional reality. In this way, the mentioned limitations can be overcome. Besides, Aguilar et al. [28] corroborate this conclusion by stating that institutions have not yet considered how to help agents in decision-making, helping achieve their own goals. An open question of models of artificial institutions is the support to the agents' reasoning on goal achievement in institutional contexts.

\section{Model}

As stated in the introduction, our conceptual model proposal aims to support the definition of purposes relating to statusfunctions. This section presents our contribution, briefly describing it in Section 3.1 and explaining its components in detail in Section 3.2. The coupling of this model with other models is beyond the scope of this paper and it is not explained. The Section 3.3 shows some functions that can be used by agents to find out (i) which status functions are associated with their goals and (ii) which concrete element is making up that status function.

\subsection{Model Overview}

Purposes are the practical interests of the agents that can be satisfied by the functions associated to the status-functions (cf. Section 2.1). The purposes are defined by the agents according to their expectations. In this work, it is assumed that the expectations regard to (i) events that the agents want to produce or (ii) states of the world that they desire to reach. Thus, purposes may be either an event or a state in the environment desired by the agents. It is also fundamental that the agents understand these purposes [8, p.22] because they connect the particular goals of the agents to the functions enabled by the institution. It is important to relate the purpose with some concept present on the agents.

Agents are designed to autonomously pursue goals, that can be either declarative or procedural [29, 30, 31, 32, 33, 34]. Roughly speaking, a procedural goal is the goal to execute actions, and a declarative goal is the goal to reach certain states of affairs, i.e., it describes desired situations [35]. Declarative goals focus on the result of the execution of actions, while procedural goals focus on the actions themselves [36]. Both represent something that the agents aim to achieve. Then, if a goal is something desirable by the agent and a purpose of a status-function expresses practical interests of the agents, then it is possible to see a link between these two concepts (Figure 1). In this work, we assume that agents have goals that are directly related to the purposes of the status functions. In other words, the purposes serve to satisfy the goals of the agents if they can make a relationship between their goals and the purposes of a status-functions. In this way, an agent can understand how a status-function is useful for him (i.e., to satisfy his goals). 
Table 1. Synthesis of the analysis of related works that implement Artificial Institutions

\begin{tabular}{|c|c|c|c|c|}
\hline & \multicolumn{4}{|c|}{ Criterias } \\
\hline Papers & $\mathrm{O}$ & $\mathrm{F}$ & $\mathrm{X}$ & $\mathrm{Y}$ \\
\hline - Fornara [7] & $\checkmark$ & & Actions or institutional facts & $\begin{array}{l}\text { InstAction class with properties such } \\
\text { as: role that is responsible for action, } \\
\text { time to execution, condition to exe- } \\
\text { cution, etc. }\end{array}$ \\
\hline - Boella and van der Torre [18] & $\checkmark$ & & $\begin{array}{l}\text { Actions and natural facts (e.g. } \\
\text { fence) }\end{array}$ & Label for holder X \\
\hline - Campos et al. [14] & & $\checkmark$ & $\begin{array}{l}\text { Agents, environment and in- } \\
\text { stitution properties }\end{array}$ & $\begin{array}{l}\text { Value that represents an desirable } \\
\text { institutional goal. }\end{array}$ \\
\hline - Dastani et al. [13] & & $\checkmark$ & Actions & $\begin{array}{l}\text { Conditions(actions) and a normative } \\
\text { consequence. }\end{array}$ \\
\hline - Vazquez et al. [19] & $\checkmark$ & & Actions & $\begin{array}{l}\text { Classifies the action performed as } \\
\text { a sub-concept of some element } \\
\text { present in the constitutive state. }\end{array}$ \\
\hline - Cliffe et al. [4] & $\checkmark$ & & Institutional actions or events & Label for holder X \\
\hline - Aldewereld et al. [20] & $\checkmark$ & & Actions & Label for holder $\mathrm{X}$ \\
\hline - Cardoso and Oliveira [5] & $\checkmark$ & & $\begin{array}{l}\text { Exchange of messages } \\
\text { among agents (actions) }\end{array}$ & Commitment \\
\hline - Viganò and Colombetti [21] & $\checkmark$ & & Actions & $\begin{array}{l}\text { Status-functions with information } \\
\text { about agent, action and normative } \\
\text { condition. }\end{array}$ \\
\hline - Grossi et al. [22] & $\checkmark$ & & Actions & Label for holder X \\
\hline - Muntaner and Esteva [23] & & $\checkmark$ & Agents'goals & Institutional specification \\
\hline - Brito et al. [6] & $\checkmark$ & & $\begin{array}{l}\text { Agents, events (actions) and } \\
\text { states }\end{array}$ & Label for holder X \\
\hline
\end{tabular}

Caption

O: ontological classification

F: functional classification
X: Concrete elements considered to be the $\mathrm{X}$ of the constitutive rule Y: Meaning of $\mathrm{Y}$ in the constitutive rule
The next section formally describes a model for specifying the purposes related to status-functions so that agents can understand and use them to satisfy their social goals. The constitution of these status-functions is addressed by other works (cf.Section 2.2) and, thus, it is not addressed in this paper.

\subsection{A meta-model for coupling purposes with status- functions.}

This section presents a conceptual model for introducing purposes related to status-functions that make up artificial institutions, defining their fundamental elements, and explaining their role in the model. The definitions 3.1 until 3.4 are imported from the Situated Artificial Institution (SAI) model $[6,37]$. The contributions of this paper start in Defini- tion 3.5.

The first element to be considered in the model are the status-functions. A status is an identifier that assigns to the environmental elements an accepted position, especially in a social group. It allows the environmental elements to perform functions (associated with the status) that cannot be explained through its physical structure [9, p.07]. Because of that the name is status + functions, thus Status-Functions. According to Searle [38], status-functions mark the difference between material and institutional realities.

Definition 3.1 (Status-Functions). The set of all the statusfunctions of an institution is represented by $\mathcal{F}=\mathcal{A}_{F} \cup \mathcal{E}_{F} \cup$ $\mathcal{S}_{F} \cup \mathcal{O}_{F}$ where (i) $\mathcal{A}_{F}$ is the set of agent-status functions, (ii) 


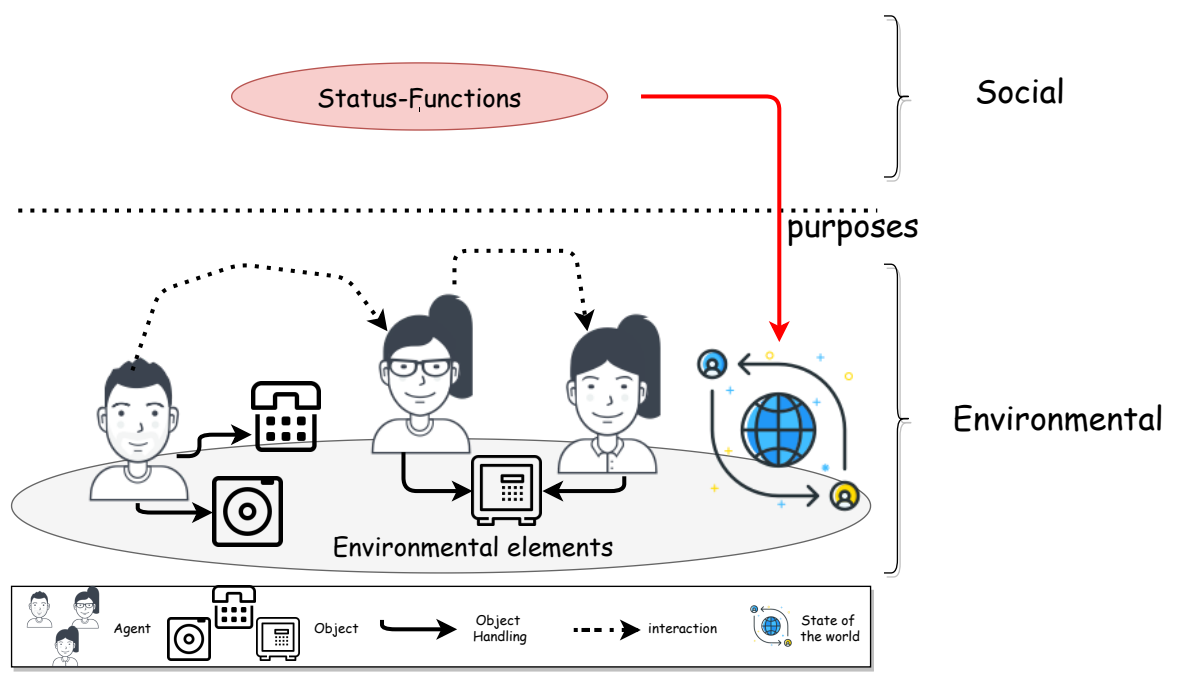

Figure 1. The situatedness of purposes in artificial institutions.

$\mathcal{E}_{F}$ is the set of event-status functions, (iii) $\mathcal{S}_{F}$ is the set of state-status functions, and (iv) $\mathcal{O}_{F}$ is the set of object-status functions. We consider that agent-status functions are statusfunctions assignable to agents, (ii) events-status functions are the status-functions assignable to events, (iii) state-status functions are the status-functions assignable to states, and (iv) object-status are the status-functions assignable to objects.

We define the kind of elements that can carry a status considering the nature of elements that compose a MAS and also the nature of the concrete elements considered by the existing works on artificial institutions. Thus, status can be assigned to:

- Agents: The agents may carry statuses that assign to them functions that are not inherent to their design. For example, in an e-commerce scenario, an agent may be implemented with expertise to be a buyer and may intend to be a buyer, but without the institutional assignment of this status, it cannot play the functions of a buyer.

- Events: The agents produce events when they act upon objects in the environment and when they interact among themselves [39]. The events may have a special interpretation in an institution. For example, the event corresponding to the transfer of a amount of money to other agent may have the status of payment, finished debt, etc., depending on the institutional assignments.

- States: Some states of the environment may have a meaning in the institution [39]. For example, the finished action of get a book may mean, in the institution, the state "own a book". This state can be related with the goal of any agent.

- Objects: some objects in the system may have some institutional significance that is not due to their physical characteristics. For example, money or cash machine objects can be used in the environment for specific purposes.

For example, these sets can be composed as follow: $\mathcal{A}_{F}=$ $\{$ buyer, seller $\}, \mathcal{E}_{F}=\{$ payment, cash pay $\}, \mathcal{S}_{F}=\{$ commerce(zone),max_time_to_response $\}$ and $\mathcal{O}_{F}=\{$ money,book $\}$. $\mathcal{F}=\{$ buyer, seller, payment, cash pay, commerce $(z o n e)$, max time to_response, money, book $\}$.

The second element to be considered in the model is the environmental elements that compose a MAS, since the purposes are related to events and states that occur in the environment.

Definition 3.2 (Environmental elements). The elements of the environment that are relevant to the institution are represented by $\mathcal{X}=\left\{\mathcal{A}_{X}, \mathcal{E}_{X}, \mathcal{S}_{X}, \mathcal{O}_{X}\right\}$ where $\mathcal{A}_{X}$ is the set of agents possibly acting in the system, (ii) $\mathcal{E}_{X}$ is the set of events that may happen in the environment, (iii) $\mathcal{S}_{X}$ is the set of possible properties used to describe the state of the environment and (iv) $\mathcal{O}_{X}$ is the set of objects that can compose the environment.

For example, these sets can be composed as follow: $\mathcal{A}_{X}=$ $\{$ bob,tom $\}, \mathcal{E}_{X}=\{$ transfer, deliver a paper note $\}, \mathcal{S}_{X}=$ $\{$ buyer send offer to seller, have a book, sell a book\} and $\mathcal{O}_{X}=\{$ many pages, paper note $\}$. In this case, $X=\{b o b$, tom, transfer, deliver a paper note, buyer send to of fer to seller, have a book, sell a book, many pages, paper note\}.

The third element to be considered in the model is constitutive rules. They specify the constitution of status-functions from environmental elements. Searle proposes to express these rules as $X$ count-as $Y$ in $C$, where $X$ represents an environmental element (i.e., a brute fact), $Y$ represents a statusfunctions and $C$ represents the context under which the constitution takes place [6]. Since the process of constitution is 
beyond the scope of this paper, the element $C$ can be ignored. For simplicity, a constitutive rule is hereinafter expressed as $X$ count-as $Y$.

Definition 3.3 (Constitutive rules). The set of all constitutive rules of an institution is represented by $\mathcal{C}$. A constitutive rule $c \subseteq \mathcal{C}$ is a tuple $\langle x, y\rangle$, where $x \in \mathcal{X}$ and $y \in \mathcal{F}$, meaning that $x$ count-as $y$.

The fourth element to be considered in the model is the status-function assignments. The constitution process produces status-function assignments (SFA). The set of all the SFA of an institution composes its constitutive state. As previously stated, the constitution process is outside the scope of this work. We represent it minimally in this paper (only considering the $\mathrm{X}$ and $\mathrm{Y}$ elements of Searle's formula) so that the reader can understand the definitions that will follow.

Definition 3.4 (Constitutive state). The constitutive state is the set of the existing SFAs. It is represented by $\mathcal{A}=\mathcal{A}_{A} \cup$ $\mathcal{E}_{A} \cup \mathcal{S}_{A} \cup \mathcal{O}_{A}$, where (i) $\mathcal{A}_{A} \subseteq \mathcal{A}_{X} x \mathcal{A}_{F}$ is the set of agentSFAs, (ii) $\mathcal{E}_{A} \subseteq \mathcal{E}_{X} x \mathcal{E}_{F}$ is the set of event-SFAs, (iii) $\mathcal{S}_{A} \subseteq$ $\mathcal{S}_{X} x \mathcal{S}_{F}$ is the set of state-SFAs and (iv) $\mathcal{O}_{A} \subseteq \mathcal{O}_{X} x \mathcal{O}_{F}$ is the set of object-SFAs.

Elements of $\mathcal{A}_{A}$ are pairs $\left\langle\mathrm{a}_{x}, \mathrm{a}_{f}\right\rangle$ s.t $\mathrm{a}_{x} \in \mathcal{A}_{X}$ and $\mathrm{a}_{f} \in \mathcal{A}_{F}$ meaning that agent $\mathrm{a}_{x}$ has the status-function $\mathrm{a}_{f}$. Elements of $\mathcal{E}_{A}$ are pairs $\left\langle\mathrm{e}_{x}, \mathrm{e}_{f}\right\rangle$ s.t $\mathrm{e}_{x} \in \mathcal{E}_{X}$ and $\mathrm{e}_{f} \in \mathcal{E}_{F}$ meaning that event $\mathrm{e}_{x}$ has the status-function $\mathrm{e}_{f}$. Elements of $\mathcal{S}_{A}$ are pairs $\left\langle\mathrm{s}_{x}, \mathrm{~s}_{f}\right\rangle$ s.t $\mathrm{s}_{x} \in \mathcal{S}_{X}$ and $\mathrm{s}_{f} \in \mathcal{S}_{F}$ meaning that state $\mathrm{s}_{x}$ has the status-function $\mathrm{s}_{f}$. Elements of $\mathcal{O}_{A}$ are pairs $\left\langle\mathrm{o}_{x}, \mathrm{o}_{f}\right\rangle$ s.t $\mathrm{o}_{x} \in$ $\mathcal{O}_{X}$ and $\mathrm{o}_{f} \in \mathcal{O}_{F}$ meaning that object $\mathrm{o}_{x}$ has the status-function $\mathrm{o}_{f}$.

For example, these sets can be composed as follow: $\mathcal{A}_{A}=$ $\{\langle$ bob, buyer $\rangle,\langle$ tom, seller $\rangle\}, \mathcal{E}_{A}=\{\langle$ transfer, payment $\rangle$, $\langle$ deliver a paper note, cash pay $\rangle\}, \mathcal{S}_{A}=\{\langle$ ntick(6001), max_time_to_inform $\rangle,\langle$ buyer send of fer to seller, commerce (zo$n e)\rangle\}, \mathcal{O}_{A}=\{\langle$ paper note, money $\rangle,\langle$ many pages, book $\rangle$. In this case, $\mathcal{A}=\{\langle$ bob, buyer $\rangle,\langle$ tom, seller $\rangle,\langle$ transfer, payment $\rangle,\langle$ deliver a paper note, cash pay $\rangle,\langle$ ntick(6001), max_time_to_inform $\rangle,\langle$ buyer send offer to seller, commerce (zo$n e)\rangle,\langle$ paper note, money $\rangle,\langle$ many pages, book $\rangle\}$.

The fifth element to be considered in the model consist of the purposes. According to section 2.1, the purposes are related to the agents' practical interests. We assume that the purposes may be both an event or a state in the environment. We consider both (i.e., events and states) in the status-functions' purposes because purposes are a way to agents reach their goals. The agents' goals can be declarative, i.e., focus on the result of the execution of actions. The result normally is a new state of the system. Besides, agents' goals also can be procedural, i.e., focus on the action themselves. It is assumed that the actions of the agents raise events in the system.

Definition 3.5 (Purposes). the purposes are expressed by $\mathcal{P}=$ $\mathcal{P}_{E} \cup \mathcal{P}_{S}$ s.t $\mathcal{P}_{E} \subseteq \mathcal{E}_{x}$ and $\mathcal{P}_{S} \subseteq \mathcal{S}_{x}$, where (i) $\mathcal{P}_{E}$ is the set of purposes related to events may happen in the environment and (ii) $\mathcal{P}_{S}$ is the set of purposes related to states that may prevail in the system.

For example, these sets can be composed as follow: $\mathcal{P}_{E}=$ $\{$ transfer, deliver a paper note $\}, \mathcal{P}_{S}=\{$ have a book, sell a book $\}$. In this case, $\mathcal{P}=\{$ transfer, deliver a paper note, have a book, sell a book\}.

The sixth element to be considered in the model is the relationship between purposes and status-functions. In the introduction of this section, we define that purposes are the agents' practical interests that can be satisfied by the functions associated with the status-functions. Thus, there must be a relationship between these two concepts.

Definition 3.6 (Relationship between purposes and statusfunctions). The relationship $\mathcal{F}_{P}$ is expressed by pairs $\langle\mathrm{f}, \mathrm{p}\rangle$ s.t. $\langle f, p\rangle \in \mathcal{F} x \mathcal{P}$, where $f \in \mathcal{F}$ and $p \in \mathcal{P}$.

For example, this set can be composed as follow: $\mathcal{F}_{P}=$ $\{\langle$ payment, have a book $\rangle,\langle$ payment, sell a book $\rangle$, meaning that payment status-function has two purposes associated: have a book and sell a book.

From these definitions, we can define the model.

Definition 3.7 (Model). The model is a tuple $\left\langle\mathcal{F}, \mathcal{P}, \mathcal{F}_{P}\right\rangle$, where $\mathcal{F}$ is the set of status-functions, $\mathcal{P}$ is the set of purposes and $\mathcal{F}_{P}$ is set that expresses the relationship between the $\mathcal{F}$ and $\mathcal{P}$ sets.

\subsection{Support functions for agents' reasoning}

Goal is a fundamental concept to understand and program MAS (cf. Section 1). This work proposes a link between the agents' goals and status-functions' purposes. This link is formally represented through the functions defined as follows.

Definition 3.8 (Mapping purposes to status-functions). Given a set $\mathcal{P}$ of purposes and a set $\mathcal{F}$ of status-functions, the set of status-functions that satisfies a purpose is given by the function $f: \mathcal{P} \rightarrow \mathcal{F}$ s.t. $f(p)=\left\{\mathrm{f} \mid(\mathfrak{f}, p) \in \mathcal{F}_{P}\right\}$.

The function $f(p)$ maps the SFs that, when constituted, satisfy the purpose $p$. For example if $\mathcal{F}=\{$ payment $\}, \mathcal{P}=$ $\{$ have a book, sell a book $\}$ and $\mathcal{F}_{P}=\{\langle$ payment, have a book $\rangle$, 
$\langle$ payment, sell a book $\}$, then $f$ (have a book $)=\{\mathrm{f} \mid$ (payment, have a book $\left.) \in \mathcal{F}_{P}\right\}$ where $f=\{$ payment $\}$. It enables the agents to exploit the constitution of payment status-functions to satisfy their social goals. To this end, it is necessary to verify the concrete elements that constitute the status-function that satisfies a social goal according to the function defined in the sequence.

Definition 3.9 (Mapping concrete elements to their assigned status-functions). Given a set $\mathcal{F}$ of status-functions and a constitutive state $\mathcal{A}$, the set of environmental elements that constitute a status-function $\mathrm{f}$ is given by the the function $f: \mathcal{F} \rightarrow \mathcal{A}$ s.t. $f(f)=\left\{\mathrm{a} \mid(\mathrm{a}, \mathrm{f}) \in \mathcal{E}_{A} \cup \mathcal{S}_{A}\right\}$.

The function $f(f)$ maps the concrete element constituting the status-functions. For example if $\mathcal{E}_{A}=\{\langle$ transfer, payment $\rangle,\langle$ deliver a paper note, cash pay $\rangle\}$ and $\mathcal{S}_{A}=\{\langle$ ntick ( $6001)$, max_time_to_inform $\rangle$, then $f($ payment $)=\{a \mid$ (transfer,payment $\left.) \in \mathcal{E}_{A} \cup \mathcal{S}_{A}\right\}$ where $a=\{$ transfer $\}$. From this, the agent knows what concrete action is counting as payment in the institutional specification and if he execute the transfer action, he can satisfy their social goal.

\section{Examples}

This section presents some examples to illustrate how the model can be used and how the agents can benefit from this use. The Subsection 4.1 shows the example related to Book commerce scenario. In this example, both agents are negotiating a book. The Bob has the goal of having a book and Tom has the goal of selling a book. Both goals can be satisfied if one of them performs an action that is interpreted in a common way and is aligned with the purpose of both. Subsection 4.2 shows the example related to met between friends. Bob has the same goal as before, but now he is in another scenario. This example shows the flexibility of this model concerning the satisfaction of agents' goals since the purposes of the status-functions are operationalized by the institution.

\subsection{Example 1 - Book commerce}

To illustrate the use of this model, we recall the example introduced at the beginning of this paper: the scenario of book commerce between the agents Bob and Tom. Bob wants to achieve a state of the world in which he has a book and Tom a state of the world in which he has sold a book. To this end, $B o b$ needs to execute an action that is aligned with his goals and also with the goal of Tom. Such a system could include other status-functions but, for simplicity, we focus only on those essential to illustrate the main features of the model proposed in Section 3.

The sets $\mathcal{E}_{F}=\{$ payment $\}, \mathcal{E}_{X}=\{$ transfer $\}$ and $\mathcal{E}_{A}=$ $\{\langle$ transfer, payment $\rangle\}$ define a constitutive specification related to the book commerce scenario. The $\varepsilon_{F}$ defines the event-status functions. At this moment, it is important to remember that this work did not consider the $C$ (i.e., the context) of Searle's formula to realize constitutions. The work is also not intended to make constitutions of status functions. However, it is necessary to illustrate them to understand the work. Then we assume that all constitutions occur since the start of the system. The event that may happen in the environment is expressed by $\mathcal{E}_{X}$ set. The $\mathcal{E}_{A}$ set define the constitution of status-functions in the concrete element. That is, the event transfer constitutes the payment status-functions.

The sets $\mathcal{P}_{S}=\{$ have a book, sold a book $\}$ and $\mathcal{F}_{P}=$ $\{\langle$ payment, have a book $\rangle,\langle$ payment, sold a book $\rangle\}$ define the purposes for the scenario and their relationship with statusfunctions. Remember that a purpose can be a event or a state that may happen in the environment. The $\mathcal{P}_{S}$ set expresses purposes related to state of the system. The $\mathcal{F}_{P}$ set expresses the relationship between the status-function and the purpose. In this case, the payment status-function has purpose of have a book and sold a book. The results of adding purposes related to status-functions are discussed below.

Discussion of the book commerce example: The agents can use the specifications of the sets $\mathcal{E}_{F}, \mathcal{E}_{A}$ and $\mathcal{F}_{P}$ to reason about how to act in the system and reach their goals. The input of the reason is the agent' goal. For example, Bob has the goal of have a book. In this case, Bob can use a function $f($ have a book $)=\{\mathrm{f} \mid$ (payment, have a book $\left.) \in \mathcal{F}_{P}\right\}$ that results in $\mathrm{f}=\{$ payment $\}$. Bob can know that his goal can be satisfied by payment status-functions. The next step is $B o b$ finding out which concrete element is constituting this status-function. For this, Bob uses another function $f($ payment $)=\left\{\right.$ a $\mid($ transfer, payment $\left.) \in \mathcal{E}_{A} \cup \mathcal{S}_{A}\right\}$ that results in a $=\{$ transfer $\}$. Therefore, Bob knows also that transfer action count-as payment and payment is related to have a book purpose, which is precisely his goal. Similarly, Tom can conclude by looking at the $\mathcal{F}_{P}$ set that the payment status-functions is related to the purpose of sold a book, which is his goal. The addition of purposes related to status-functions allows the agents to use status-functions to achieve their goals without considering regulative norms. Therefore, both $B o b$ and Tom can achieve their social goals (i.e., the goal that requires a common interpretation of actions) without difficulty.

\subsection{Example 2 - Meeting between friends who like books}

We can now consider the same agent $B o b$ and his goal of having a book. However, we changed some things in this example: (i) Tom is passionate about books, so he has many books in his house. (ii) Tom is out of space on his shelf, so his goal is to vacate a shelf space. Besides, Tom is a friend of $B o b$ and (iii) Bob and Tom are in Tom's house.

The sets $\mathcal{A}_{F}=\{$ friend $\}, \mathcal{E}_{F}=\{$ borrow a book $\}, \mathcal{S}_{F}=$ $\{$ talking between friends $\}, \mathcal{O}_{F}=\{$ book $\}, \mathcal{A}_{X}=\{$ bob,tom $\}$, $\mathcal{E}_{X}=\{$ order a book $\}, \mathcal{S}_{X}=\{$ bob send a message to tom,tom send a message to bob $\}, \mathcal{O}_{X}=\{$ many pages $\}, \mathcal{A}_{A}=\{\langle$ bob, 
friend $\rangle\langle$ tom, friend $\rangle\}, \mathcal{E}_{A}=\{\langle$ order a book, borrow a book $\rangle$ \},$S_{A}=\{\langle$ bob send a message to tom, taking between friends \rangle$,\langle$ tom send a message to bob,taking between friends $\rangle\}$ and $\mathcal{O}_{A}=\{\langle$ many pages, book $\rangle\}$ define a constitutive specification for this example. The sets $\mathcal{A}_{F}, \mathcal{E}_{F}, \mathcal{S}_{F}$ and $\mathcal{O}_{F}$ define the status-functions. Agents may have the status-function of Friend. The events may have the status-function of borrow a book. The state-status function talking between friends is defined to express a situation in the interaction between agents in this scenario. Finally, the object-status function book refer to objects that can there are in the environment.

The constitutive rules of the example are defined by $\mathcal{A}_{A}$, $\mathcal{E}_{A}, \mathcal{S}_{A}$ and $\mathcal{O}_{A}$ sets. The $\mathcal{A}_{A}$ set express constitutions related to agents. Bob and Tom count-as friend. The $\mathcal{E}_{A}$ set express a constitutive rule related to events that occur in the environment. In this case, ordering a book count-as to borrow a book (we do not consider the time interval between the book owner agent accepting the order, etc.). The $\mathcal{S}_{A}$ set express constitutive rules related to states the system that can be maintained. Both states involves the interaction between Bob and Tom. This interaction count-as talking between friends. Finally, the $\mathcal{O}_{A}$ set express a constitutive rule related to an object that can there is in the environment.

The sets $\mathcal{P}_{S}=\{$ have a book, vacate a shelf space $\}$ and $\mathcal{F}_{P}=\{\langle$ borrow a book, have a book $\rangle,\langle$ borrow a book, vacate a shelf book $\rangle$ define the purposes for this example. The $\mathcal{P}_{S}$ set express purposes related to states of the system. The $\mathcal{F}_{P}$ set express the relationship between the status-functions and the purposes. In this case, the borrow a book status-function is related to the purposes of have a book and vacate a shelf space.

Discussion of the meeting between friends who like books example: From $\mathcal{A}_{A}$ set, both agents can understand they are constituting the friend status-functions. In this example, this constitution is used as just an illustration. However, the friend status-function may be related to a set of regulative norms in another scenario. From $\mathcal{E}_{A}$ set, the agents know what action is interpreted by the institution as borrow a book. Similarly, through $\mathcal{S}_{A}$ and $\mathcal{O}_{A}$ agents can know that is constituting states of the system and objects that can there are in the environment respectively.

To reason about how to act in the system and reach their goals, the agents can use the specifications of the sets $\varepsilon_{F}, \mathcal{E}_{A}$ and $\mathcal{F}_{P}$. In this case, Bob can use a function $f($ have a book) $=$ $\left\{\mathrm{f} \mid(\right.$ borrow a book, have a book $\left.) \in \mathcal{F}_{P}\right\}$ that results in $\mathrm{f}=$ \{borrow a book\}. Bob can know that his goal can be satisfied by borrow a book status-functions. The next step is $B o b$ finding out which concrete element is constituting this status-function. For this, $B o b$ uses another function $f($ borrow a book $)=\{\mathrm{a} \mid($ order a book, borrow a book $) \in$ $\left.\mathcal{E}_{A} \cup \mathcal{S}_{A}\right\}$ that results in a $=\{$ order a book $\}$. Therefore, $B o b$ knows also that order a book action count-as borrow a book and borrow a book is related to have a book purpose, which is precisely his goal. Similarly, Tom can conclude by looking at the $\mathcal{F}_{P}$ set that borrow a book status-functions is related to the purpose of vacate a shelf space, that is his goal. Therefore, through the interpretation of the institutional and purposes specification, both Bob and Tom can know how to reach their goals in this scenario.

Besides that, the sets $\mathcal{A}_{A}, \mathcal{S}_{A}$ and $\mathcal{O}_{A}$ show other constitutive rules just to illustrate the possibilities of using an institution. In another example, maybe the constitutive rules expressed by $\mathcal{S}_{A}$ could be fundamental to validate the borrow $a$ book between Bob and Tom.

\section{Using the model in a Multi-Agent Sys- tem}

To illustrate the proposal in a computational scenario, we consider the implementation an open Multi-Agent System composed of agents, environment and institution. The example is the same as the presented in Section 4.1. The agents Bob and Tom aim to have a book and sold a book respectively and are located in a book store (Figure 2). This system is instrumented with an institution that contains only a constitutive rule stating that the concrete action transfer count-as pay. Such a system could include other status-functions and constitutive rules but, for simplicity, we focus only on this case to illustrate the main features of the model proposed (cf. Section 3.2).

The example is available at https://github.com/rafhaelrc/ psf_model. It is implemented using the JaCaMo Framework [29] (cf. Figure 3). The agents (Bob and Tom in Figure 2) are coded in Jason [40] and the environment in CArtAgO [41]. The artificial institution (Institutional specification in Figure 2) is an implementation of the Situated Artificial Institution (SAI) model [37]. In SAI, the institutional reality is composed of status-functions attributed to concrete elements through the interpretation of constitutive rules. To implement the model proposed in this work (Institutional purpose specification in the Figure 2), we use ontologies. Finally, to make the model accessible to agents, we encapsulated it in a CartAgO artifact. The support for queries and persistence of data in the ontology is based on MasOntology 1 , a set of tools developed in CArtAgO to integrate ontologies and MAS.

Figure 4 depicts the agents program. The code of all agents are similar, varying only the term they use to refer to their social goals (e.g., haveBook, soldBook) . The agents' social goals can be satisfied by the plans illustrated in line 4 of each piece of code of Figure 4. These plans create a sub-goal, identified by commonPurpose, that finds the action that satisfies the purposed related to such a social goal in the institution. The commonPurpose goals can be achieved by the plan detailed in Figure 4 (C). This plan is the same for all the agents. It could be even imported from a library of purpose-related plans. In this excerpt, first the agent consults the ontology (which is a representation of the model) using the isPurposeOfStatusFunction operation encoded in a CartAgO artifact (line 9). This operation has as its first parameter the term used by the agent to refer to its social goal and the second

\footnotetext{
${ }^{1}$ https://github.com/smart-pucrs/MasOntology
} 


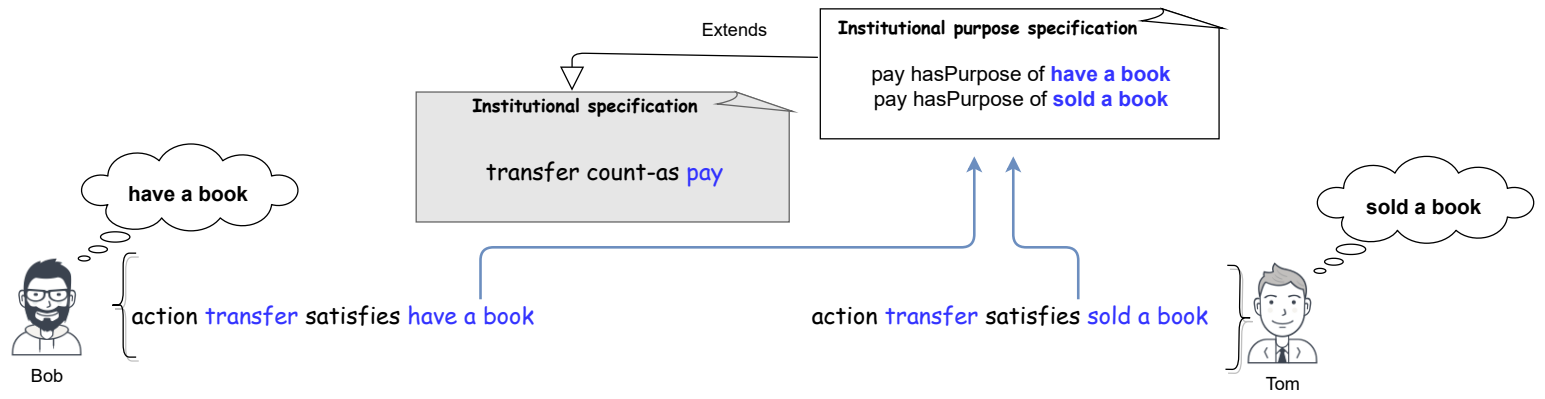

Figure 2. Use of the proposed model in an institutional specification.

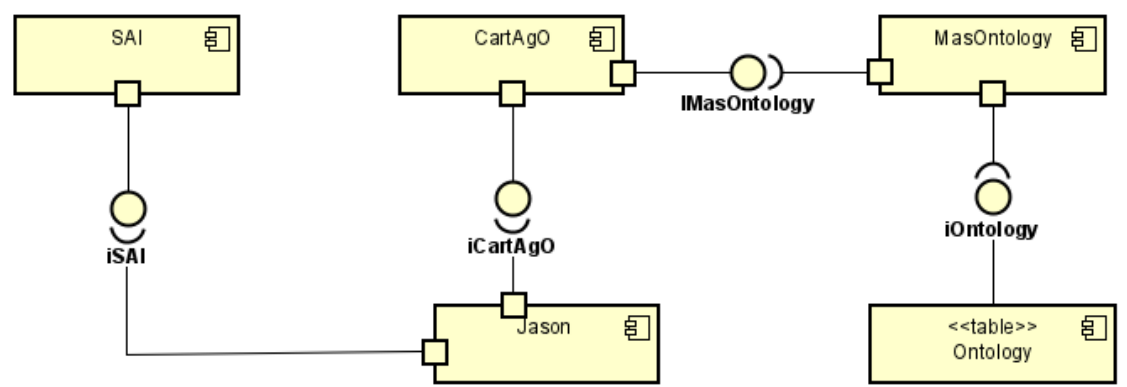

Figure 3. Component diagram with the systems used to compose the example.

parameter (if any) is the concrete elements that are related to the purpose (for example, the name of a book). When performing this operation, the agent obtains in the third parameter the status-function that satisfies the purpose. Second, the agent consults which concrete action may constitute the found status-function (line 10). Finally, the agent executes the action, eventually satisfying the social goal (line 11). Table 2 briefly shows the execution of agent Bob in the example. Tom is executed similarly, varying only the time 0 and 1 according to their social goals. From these steps, all agents are able to achieve their different social goals in the same institution.

The example of Section 4.2 is not included here. However, the steps for its implementation are pretty similar. The variations are (i) Tom's goal (in this example his goal is to vacate a shelf space rather than sold a book) and (ii) the specification of institutional purposes.

\section{Results and Discussion}

The problem motivating this paper is the common interpretation of the agents about certain facts that occur in the environment. This problem is partially solved by computational models that implement artificial institutions and interpret certain facts about the environment from an institutional perspective. However, these models do not provide the purpose of this interpretation from an agent perspective. That is, agents cannot know which status-functions can be useful for them to achieve their social goals. Considering this problem, we propose the conceptual model to express the purposes associated with the status-functions that composes the artificial institutions presents on the MAS. The conception of our model is an adaptation, from a particular point of view, of Searle's theory $[8,9]$ which claims that the purposes are specified by practical interests of the individuals that can be satisfied by the functions associated to the status-functions (cf. Section 2.1). We assume that the purposes are defined based on the interests of the agents. However, they are specified by a party involved in the development of the system. In other words, it is not the agents themselves who define the purposes based on collective agreements, etc.

There are some advantages of such a conception that we will discussed below. The first advantage is related to the flexibility of agents being programmed by different programmers in different ways, and even so, they can reach their goals. For example, the subsection 4.1 illustrates a scenario of buy and sell of books between two agents ( Bob and Tom). We can imagine some situations for this scenario: (i) $B o b$ was specified by different programmers, and Tom was also specified by different programmers. With the addition of purposes related to status-functions, the institution itself gives the meaning for the status-functions constituted. Even the agents can understand how to reach their goals. (ii) Alice (or any other agent) can enter in the system with the goal of acquire a book. With the addition of purposes, it is necessary to specify that Alice's goal is related to a status function's purpose. In this way, it is not necessary to modify Alice's coding or the environment or institution to achieve her goal. Both situations are critical in open MAS, where these elements are not necessarily known at design time $[42,43]$. This example shows the flexibility of this model's addition. Different agents (designed and programmed by different people for different reasons) enter the same environment and reach their goals.

The second advantage is related to the possibility of the same agent entering and exiting different environments and, 
We plan to also address more practical points such as (i) the integration of this model in other models that implement artificial institutions, (ii) the implementation of a library that generalizes the use of the model and (iii) the use of the model in real scenarios.

\section{Acknowledgements}

This study was supported by the Federal Institute of Education, Science and Technology of Rio Grande do Sul (IFRS).

\section{Author contributions}

- Rafhael Rodrigues Cunha: Investigation, Methodology, Software, Validation, Writing - Review \& Editing.

- Jomi Fred Hübner: Conceptualization, Writing - Review \& Editing, Supervision.

- Maiquel de Brito: Conceptualization, Visualization, Writing - Original Draft, Supervision.

\section{References}

[1] WOOLDRIDGE, M. An introduction to multiagent systems. [S.1.]: John Wiley \& Sons, 2009.

[2] WINIKOFF, M. Challenges and directions for engineering multi-agent systems. arXiv preprint arXiv:1209.1428, 2012.

[3] FORNARA, N.; VIGANÒ, F.; COLOMBETTI, M. Agent communication and artificial institutions. Autonomous Agents and Multi-Agent Systems, v. 14, n. 2, p. 121-142, 2007.

[4] CLIFFE, O.; VOS, M. D.; PADGET, J. Answer set programming for representing and reasoning about virtual institutions. In: SPRINGER. International Workshop on Computational Logic in Multi-Agent Systems. [S.1.], 2006. p. 60-79.

[5] CARDOSO, H. L.; OLIVEIRA, E. Institutional Reality and Norms: Specifying and Monitoring Agent Organizations. International Journal of Cooperative Information Systems, v. 16, n. 01, p. 67-95, 2007.

[6] BRITO, M. d. et al. A model of institucional reality supporting the regulation in artificial institutions. Tese (Doutorado) - Universidade Federal de Santa Catarina, 2016.

[7] FORNARA, N. Specifying and monitoring obligations in open multiagent systems using semantic web technology. In: Semantic agent systems. [S.1.]: Springer, 2011. p. 25-45.

[8] SEARLE, J. R. The construction of social reality. [S.1.]: Simon and Schuster, 1995.

[9] SEARLE, J. Making the social world: The structure of human civilization. [S.1.]: Oxford University Press, 2010.
[10] FORNARA, N.; VIGANÒ, F.; COLOMBETTI, M. Agent communication and institutional reality. In: SPRINGER. International Workshop on Agent Communication. [S.1.], 2004. p. 1-17.

[11] PIUNTI, M. et al. Embodied organisations in MAS environments. Lecture Notes in Computer Science (including subseries Lecture Notes in Artificial Intelligence and Lecture Notes in Bioinformatics), v. 5774 LNAI, p. 115-127, 2009.

[12] FORNARA, N.; COLOMBETTI, M. Specifying and Enforcing Norms. n. 2204, p. 1-17, 2009.

[13] DASTANI, M. et al. Normative multi-agent programs and their logics. In: Knowledge Representation for Agents and Multi-Agent Systems. [S.1.]: Springer, 2009. p. 16-31.

[14] CAMPOS, J. et al. Formalising Situatedness and Adaptation in. p. 126-139, 2009.

[15] RODRIGUEZ-AGUILAR, J. A. et al. Towards next generation coordination infrastructures. Knowledge Engineering Review, 2015, vol. 30, num. 4, p. 1-19, Cambridge University Press, 2015.

[16] CONDELLO, A.; FERRARIS, M.; SEARLE, J. R. Money, Social Ontology and Law. [S.1.]: Routledge, 2019.

[17] CONDELLO, A. Two questions on the ontology of money. Ardeth, n. 03, p. 181-191, 2018.

[18] BOELLA, G.; TORRE, L. van der. Regulative and constitutive norms in normative multiagent systems. $K R$, v. 4 , p. 255-265, 2004.

[19] VÁZQUEZ-SALCEDA, J. et al. From human regulations to regulated software agents' behavior. Artificial Intelligence and Law, Springer, v. 16, n. 1, p. 73-87, 2008.

[20] ALDEWERELD, H. et al. Making norms concrete. In: INTERNATIONAL FOUNDATION FOR AUTONOMOUS AGENTS AND MULTIAGENT SYSTEMS. Proceedings of the 9th International Conference on Autonomous Agents and Multiagent Systems: volume 1-Volume 1. [S.1.], 2010. p. 807-814.

[21] VIGANÒ, F.; COLOMBETTI, M. Model Checking Norms and Sanctions in Institutions. n. ii, p. 316-329, 2008.

[22] GROSSI, D. et al. Ontological aspects of the implementation of norms in agent-based electronic institutions. Computational and Mathematical Organization Theory, v. 12, n. 2-3 SPEC. ISS., p. 251-275, 2006.

[23] MUNTANER, E.; ESTEVA, J. L. Towards a formalisation of dynamic electronic institutions. In: SPRINGER. International Workshop on Coordination, Organizations, Institutions, and Norms in Agent Systems. [S.1.], 2007. p. 97-109.

[24] CLIFFE, O.; VOS, M. D.; PADGET, J. Specifying and reasoning about multiple institutions. In: SPRINGER. International Workshop on Coordination, Organizations, Institutions, and Norms in Agent Systems. [S.1.], 2006. p. 67-85. 
[25] FORNARA, N.; COLOMBETTI, M. Ontology and time evolution of obligations and prohibitions using semantic web technology. In: SPRINGER. International Workshop on Declarative Agent Languages and Technologies. [S.1.], 2009. p. 101-118.

[26] FORNARA, N.; COLOMBETTI, M. Representation and monitoring of commitments and norms using owl. AI communications, IOS Press, v. 23, n. 4, p. 341-356, 2010.

[27] FORNARA, N.; TAMPITSIKAS, C. Using owl artificial institutions for dynamically creating open spaces of interaction. In: AT. [S.1.: s.n.], 2012. p. 281-295.

[28] RODRIGUEZ-AGUILAR, J. A. et al. Towards next generation coordination infrastructures. Knowledge Engineering Review, v. 30, n. 4, p. 435-453, 2015.

[29] BOISSIER, O. et al. Multi-agent oriented programming: programming multi-agent systems using JaCaMo. [S.l.]: MIT Press, 2020.

[30] WINIKOFF, M. et al. Declarative and procedural goals in intelligent agent systems. In: MORGAN KAUFMAN. International Conference on Principles of Knowledge Representation and Reasoning. [S.1.], 2002.

[31] HINDRIKS, K. V. et al. Agent programming with declarative goals. In: SPRINGER. International Workshop on Agent Theories, Architectures, and Languages. [S.1.], 2000. p. 228-243.

[32] RIEMSDIJK, B. van; HOEK, W. van der; MEYER, J.-J. C. Agent programming in dribble: from beliefs to goals using plans. In: Proceedings of the second international joint conference on Autonomous agents and multiagent systems. [S.1.: s.n.], 2003. p. 393-400.

[33] HÜBNER, J. F.; BORDINI, R. H.; WOOLDRIDGE, M. Declarative goal patterns for agentspeak. In: Proceedings of the Fifth International Joint Conference on Autonomous Agents and Multiagent Systems (AAMAS'06). [S.1.: s.n.], 2006.

[34] NIGAM, V.; LEITE, J. A dynamic logic programming based system for agents with declarative goals. In:

SPRINGER. International Workshop on Declarative Agent Languages and Technologies. [S.1.], 2006. p. 174-190.

[35] RIEMSDIJK, M. B. van. Cognitive agent programming: A semantic approach. [S.1.]: Utrecht University, 2006.

[36] RIEMSDIJK, M. B. V.; DASTANI, M.; WINIKOFF, M. Goals in agent systems: A unifying framework. In: Proceedings of the 7th international joint conference on Autonomous agents and multiagent systems-Volume 2. [S.1.: s.n.], 2008. p. 713-720.

[37] BRITO, M. D.; HÜBNER, J. F.; BOISSIER, O. Situated artificial institutions: stability, consistency, and flexibility in the regulation of agent societies. Autonomous Agents and Multi-Agent Systems, Springer, v. 32, n. 2, p. 219-251, 2018.
[38] SEARLE, J. R. Social ontology: Some basic principles. Anthropological theory, SAGE Publications London, Thousand Oaks, CA and New Delhi, v. 6, n. 1, p. 12-29, 2006.

[39] BRITO, M. D.; HÜBNER, J. F.; BOISSIER, O. A conceptual model for situated artificial institutions. In: SPRINGER. International Workshop on Computational Logic and Multi-Agent Systems. [S.1.], 2014. p. 35-51.

[40] BORDINI, R. H.; HÜBNER, J. F.; WOOLDRIDGE, M. Programming multi-agent systems in AgentSpeak using Jason. [S.1.]: John Wiley \& Sons, 2007. v. 8.

[41] RICCI, A.; PIUNTI, M.; VIROLI, M. Environment programming in multi-agent systems: an artifact-based perspective. Autonomous Agents and Multi-Agent Systems, Springer, v. 23, n. 2, p. 158-192, 2011.

[42] ALDEWERELD, H.; DIGNUM, V. Operetta: Organization-oriented development environment. In: SPRINGER. International Workshop on Languages, Methodologies and Development Tools for Multi-Agent Systems. [S.1.], 2010. p. 1-18.

[43] ZAMBONELLI, F.; JENNINGS, N. R.; WOOLDRIDGE, M. Organisational abstractions for the analysis and design of multi-agent systems. In: SPRINGER. International Workshop on Agent-Oriented Software Engineering. [S.1.], 2000. p. 235-251.

[44] De Brito, M.; HÜUBNER, J. F. A Conceptual Model for Situated Artificial Institutions. Lecture Notes in Computer Science (including subseries Lecture Notes in Artificial Intelligence and Lecture Notes in Bioinformatics), v. 8624 LNAI, n. March 2016, 2014.

[45] TELANG, P. R.; SINGH, M. P.; YORKE-SMITH, N. A coupled operational semantics for goals and commitments. Journal of Artificial Intelligence Research, v. 65, p. 31-85, 2019.

[46] TOMIC, S.; PECORA, F.; SAFFIOTTI, A. Norms, Institutions, and Robots. v. 14, n. 8, p. 1-14, 2018. Disponível em: 〈http://arxiv.org/abs/1807.11456〉.

[47] MURRAY-RUST, D.; PAPAPANAGIOTOU, P.; ROBERTSON, D. Softening electronic institutions to support natural interaction. Human Computation, v. 2, n. 2, 2015.

[48] PADGET, J.; De Vos, M.; PAGE, C. A. Deontic sensors. IJCAI International Joint Conference on Artificial Intelligence, v. 2018-July, n. section 5, p. 475-481, 2018.

[49] COSTA, A. C. da R.; DIMURO, G. P. Elementary social functions: Concept and interrelation to social dependence relations. In: IEEE. 2012 Third Brazilian Workshop on Social Simulation. [S.1.], 2012. p. 23-30. 